\title{
Ordering Decision in Dual-sourcing Supply Chain with Substitute Product
}

\author{
Guoyu $\mathrm{Ni}^{1, a}$ and Yong $\mathrm{Xie}^{2, \mathrm{~b}}$ \\ ${ }^{1}$ School of Automation, Huazhong University of Science and Technology, Wuhan 430074, China; \\ ${ }^{2}$ School of Automation, Huazhong University of Science and Technology, Wuhan 430074, China. \\ a15271814471@163.com, byhust@163.com
}

Keywords: substitute product, demand uncertainty, supply uncertainty, ordering decision.

\begin{abstract}
This paper builds a model of a supply chain with substitute product, which consists of a reliable supplier, an unreliable supplier and a retailer. Then I research retailers ordering decision when the supply and demand is uncertain at the same time. The results show that in a supply chain with substitute product, with the increase of inventory costs and demand uncertainty, retailers will increase the amount of orders from unreliable suppliers; and with the increase of the shortage penalty cost, retailers will increases the amount of orders from reliable suppliers. Finally, I verify the result by the Numerical example.
\end{abstract}

\section{Introduction}

With the rapid changes of market demand, retailers consider reducing the total cost by selecting the appropriate supplier. For example, in the process of building the Three Gorges, fly ash is in great demand. And there are many suppliers which have different price and reliability, the decision-makers should choose proper suppliers and proper orders so as to minimize the total cost. Considering the project duration is limited, so the orders can't be less than the demand and the number of supplier must be more than one.

Some researchers have studied retailers`ordering decision when the supply is uncertain or the demand is uncertain. So in this paper, I studied retailers`ordering decision when the supply and the demand are uncertain in the same time. And I considered the situation that the shortage penalty cost is more than the order cost. Then I built a model to help retailers make the best ordering decision in order to minimize the total cost. Finally, I verify the result by the Numerical example.

\section{The decision model of dual-sourcing supply chain with substitute product}

Model definition. This paper research a dual-sourcing supply chain with two supplier and a retailer. The supplier $S_{1}$ and supplier $S_{2}$ supply substitute product 1 and 2 , as the fig. 1 shows.

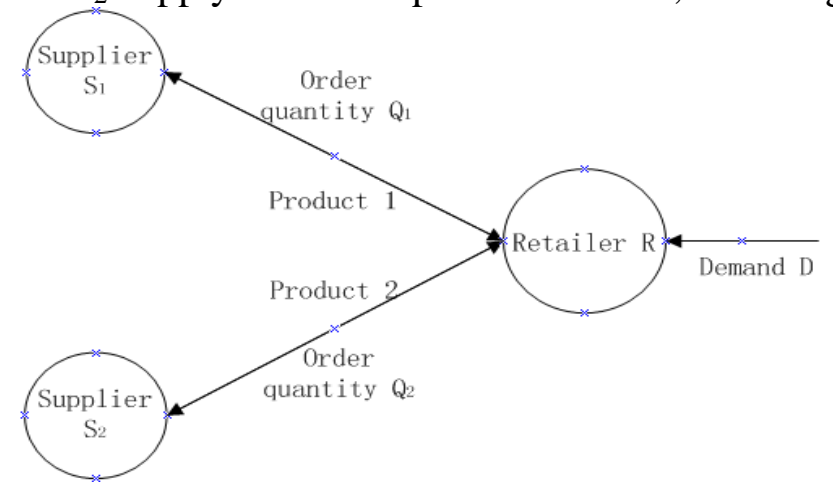

Fig. 1

(1)The price of the product 1 is $\omega_{1}$ and the order fulfillment rate is $\xi$, it means that the supplier $S_{1}$ can provide $\xi Q$ when the retailer`s order is $Q$. And $\xi$ is a continues random variable, $\xi \sim U[0,1]$ and its density function is $f_{\xi}(\xi)$;

(2)The price of the product 2 is $\omega_{2}$ and the order fulfillment rate is 1 ; 
(3)The demand is $\mathrm{D}, \mathrm{D}$ is a continues random variable, $\mathrm{D} \in\left(d_{1}, d_{2}\right)$, its density function is $f(\mathrm{D})$, its distribution function is $F(D)$, its expectation is $E(D)$ and variance is $\sigma^{2}(D)$;

(4)The order quantities from $S_{1}$ and $S_{2}$ are $Q_{1}$ and $Q_{2}$ and $Q_{1}, Q_{2} \neq 0$ considering the supply chain is dual-souring;

(5)The per-unit shortage penalty cost is e and this paper considered the situation that the shortage penalty cost is higher than the order cost, so $\omega_{1}<\omega_{2}<e$;

(6)The per-unit inventory cost is $h$;

(7) $\omega_{1}<\omega_{2}<e$, so $Q_{1}+Q_{2} \geq D$.

The decision model. The retailer`s total cost $\mathrm{C}$ consists of the shortage penalty $\operatorname{cost} \mathrm{C}_{s}$, the order $\operatorname{cost} \mathrm{C}_{\mathrm{o}}$ and the inventory cost $\mathrm{C}_{h}$. The shortage penalty cost is gaven by

$$
\mathrm{C}_{s}=e \int_{d_{1}}^{d_{2}} \int_{0}^{\frac{\mathrm{D}-\mathrm{Q}_{2}}{\mathrm{Q}_{1}}}\left(\mathrm{D}-\mathrm{Q}_{2}-\xi \mathrm{Q}_{1}\right) f(\mathrm{D}) d \xi d \mathrm{D}
$$

The order cost is given by

$$
C_{o}=\int_{0}^{1} \xi \omega_{1} Q_{1} f_{\xi}(\xi) d \xi+\omega_{2} Q_{2}
$$

The inventory cost is given by

$$
\mathrm{C}_{h}=h \int_{d_{1}}^{d_{2}} \int_{\frac{\mathrm{D}-\mathrm{Q}_{2}}{\mathrm{Q}_{1}}}^{1}\left(\xi \mathrm{Q}_{1}+\mathrm{Q}_{2}-\mathrm{D}\right) f(\mathrm{D}) d \xi d \mathrm{D}
$$

So the total cost is given by

$$
\begin{gathered}
\mathrm{C}\left(\mathrm{Q}_{1}, \mathrm{Q}_{2}\right)=\mathrm{C}_{s}+\mathrm{C}_{\mathrm{o}}+\mathrm{C}_{h} \\
=\frac{e+h}{2 \mathrm{Q}_{1}}\left(\mathrm{E}(\mathrm{D})-\mathrm{Q}_{2}\right)^{2}+\frac{h+\omega_{1}}{2} \mathrm{Q}_{1}+\left(h+\omega_{2}\right) \mathrm{Q}_{2}+\frac{e+h}{2 \mathrm{Q}_{1}} \sigma(\mathrm{D})-h \mathrm{E}(\mathrm{D})
\end{gathered}
$$

The paper aimed to minimize the retailer`s total cost and get the best order quantities $Q_{1}^{*}$ and $Q_{2}^{*}$.

Proposition: when $\left(h+\omega_{2}\right)^{2}<(e+h)\left(h+\omega_{1}\right)$, the cost function $C$ is a concave function, the best order quantities are given by

$$
\left\{\begin{array}{c}
Q_{1}^{*}=(e+h) \lambda \\
Q_{2}^{*}=E(D)-\left(h+\omega_{2}\right) \lambda
\end{array} Q_{1} \neq 0\right.
$$

the minimum cost is given by

$$
C\left(Q_{1}^{*}, Q_{2}^{*}\right)=\omega_{2} E(D)+{ }^{\sigma(D)} / \lambda \quad Q_{1} \neq 0
$$

And $\lambda=\sqrt{\frac{\sigma(\mathrm{D})}{(e+h)\left(h+\omega_{1}\right)-\left(h+\omega_{2}\right)^{2}}}$.

The Proposition shows that the retailer will order more products from supplier $\mathrm{S}_{1}$ and fewer products from supplier $S_{2}$ with the inventory cost, the price of the product 2 and the demand uncertainty increasing; the retailer will order fewer products from supplier $S_{1}$ and more product from 
supplier $S_{2}$ with the shortage penalty cost and the price of the product 1 increasing and the total cost will increase with the inventory cost, the shortage penalty cost, the price of the product 1 , the price of the product 2 and the demand uncertainty increasing.

Numerical example. The paper took $h=1, e=9, \omega_{1}=6, \omega_{2}=7, \mathrm{E}(\mathrm{D})=10, \sigma^{2}(\mathrm{D})=4$ as the benchmark to research the influence of different parameters. First, I studied the situation that the value of $h$ ranges from 0 to 7 and get $C\left(Q_{1}^{*}, Q_{2}^{*}\right), Q_{1}^{*}$ and $Q_{2}^{*}$ as fig.2 shows.
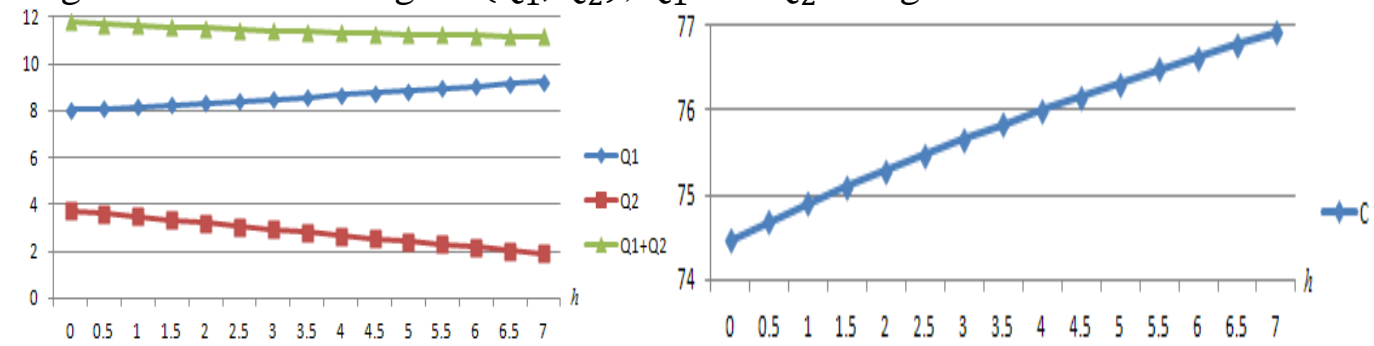

Fig. 2 the influence of the inventory cost

The fig. 2 shows that the retailer will order more products from supplier $\mathrm{S}_{1}$ and fewer products from supplier $\mathrm{S}_{2}$ with the inventory cost increasing and the total cost is increasing.

Then, I studied the situation that the value of $e$ ranges from 8.6 to 11 and get $C\left(Q_{1}^{*}, Q_{2}^{*}\right), Q_{1}^{*}$ and $Q_{2}^{*}$ as fig. 3 shows.
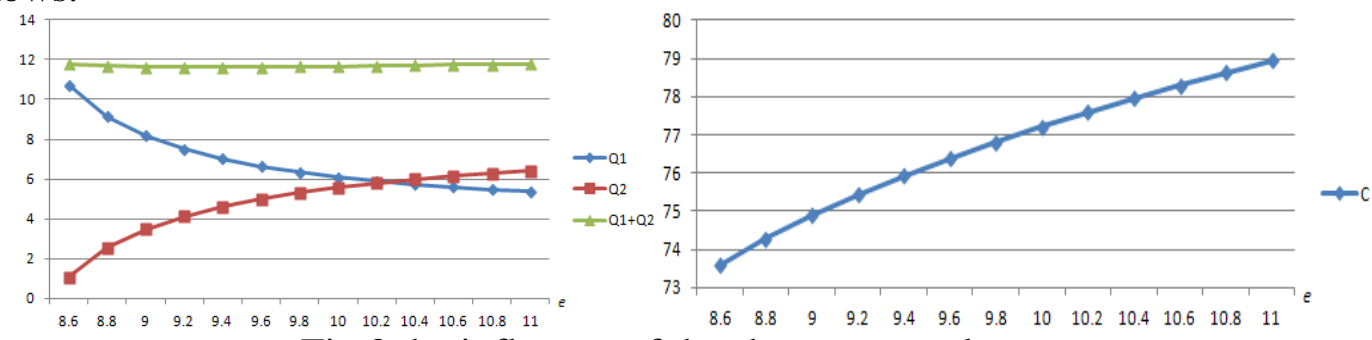

Fig.3 the influence of the shortage penalty cost

The fig. 3 shows that the retailer will order fewer products from supplier $\mathrm{S}_{1}$ and more products from supplier $S_{2}$ with the shortage penalty cost increasing and the total cost is increasing.

Finally, I studied the situation that the value of $\sigma^{2}(D)$ ranges from 8.6 to 11 and get $C\left(Q_{1}^{*}, Q_{2}^{*}\right), Q_{1}^{*}$ and $\mathrm{Q}_{2}^{*}$ as fig.4 shows.
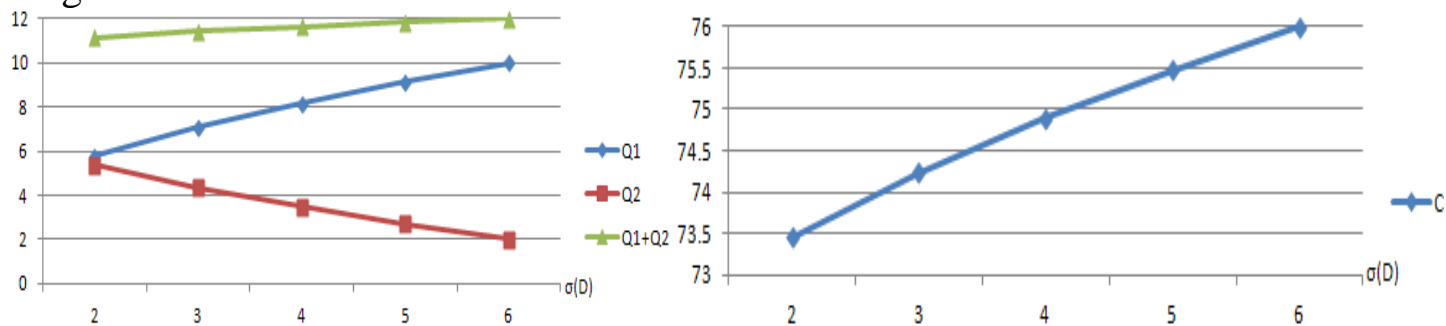

Fig. 4 the influence of the demand uncertainty

The fig. 2 shows that the retailer will order more products from supplier $S_{1}$ and fewer products from supplier $S_{2}$ with the demand uncertainty increasing and the total cost is increasing.

\section{Literature References}

In recent years, Alfred ${ }^{[1]}$ studied the influence of the lead time uncertainty on the supply chain cost and proposed improvement measures from the delivery time window, the mean and variance of delivery distribution function; $\mathrm{Wu}^{[2]}$ studied the situation that there are a supplier with long lead time and a supplier with short lead time in the supply chain, the retailer`s ordering decision considering the market situation; Ülkü ${ }^{[3]}$ studied newsboy model with two substitute products in the two-level supply chain and the situation that suppliers will buyback unsold goods; Mengshi ${ }^{[4]}$ studied the inventory strategy, order strategy and substitute strategy of two substitute products in the two-level supply chain; Varun ${ }^{[5]}$ studied the decision-makers` way to operate the supply chain when the supply chain probably disrupts, buyers`and suppliers` game strategy. 


\section{Summary}

This paper constructed a supply chain with substitute product, and the supply and demand is uncertain at the same time in this supply chain. Then this paper studied the influence of the shortage penalty cost, the inventory costs and the demand uncertainty on the retailer's ordering decision. The results show that in a supply chain with substitute product, with the increase of inventory costs and demand uncertainty, retailers will increase the amount of orders from unreliable suppliers; and with the increase of the shortage penalty cost, retailers will increases the amount of orders from reliable suppliers. Finally, I verify the result by the Numerical example.

Of course, there are some limitations and shortcomings in this paper. And I hope to improve it by intensive study in the future. First, in the decision-making process, this paper only took the retailers ` cost into account and ignored the suppliers` profit. Secondly, this paper didn`t consider the influence of lead time in the supply chain. Therefore, in the intensive study, I will study the influence of the lead time uncertainty and consider suppliers ` profit at the same time, then maximize the profit of the whole supply chain.

\section{References}

[1] Guiffrida A L, Nagi R. Cost characterizations of supply chain delivery performance[J]. International Journal of Production Economics, 2006, 102(1): 22-36.

[2] Wu X, Zhang F. Efficient supplier or responsive supplier? an analysis of sourcing strategies under competition[C]/China Business Initiative conference, sponsored by the Chazen Institute of International Business at Columbia Business School. 2011.

[3] Gürler Ü, Yilmaz A. Inventory and coordination issues with two substitutable products[J]. Applied Mathematical Modelling, 2010, 34(3): 539-551.

[4] Lu M, Huang S, Shen Z J M. Product substitution and dual sourcing under random supply failures[J]. Transportation Research Part B: Methodological, 2011, 45(8): 1251-1265.

[5] Gupta V, He B, Sethi S P. Contingent sourcing under supply disruption and competition[J]. International Journal of Production Research, 2015, 53(10): 3006-3027. 